\title{
CASTRO ALVES E A REVOLUÇÃO PRAIEIRA
}

Pernambuco é no Brasil a audaz Leoa revolucionária e nutriu, de seu leite inflamado, o poeta Antônio de Castro Alves. Este sentiu o fogo da atmosfera pernambucana, impregnada das emanações das sociedades secretas do tipo maçônico, as primeiras, pelo consenso mais geral, que se instalaram no Brasil, e em cujos recintos indevassáveis iam sendo ensinados os "mistérios" da Democracia, sonho pelo qual tanto se iria lutar e tanto se iria morrer e pelo qual Castro Alves tanto iria cantar, blasfemar, imprecar, chorar.

A Praia inspirou o poeta muito mais do que a própria Guerra do Paraguai - fulcro, durante os cinco anos que durou, de tôdas us atenções, de tôdas as esperanças e desalentos do Império. Aliás, tôra precedido nesta exaltação do movimento da Praia por Alvares de Azevedo e Pedro Luiz, que haviam iniciado o processo de dramatizaçāo, romantizaçāo, sublimaçāo da epopéia de Pedro Ivo, $\mathrm{Nu}$ nes Machado, Borges da Fonseca. Precederam-no, também, os versos do povo:

\footnotetext{
Machado que corta lenha-

Também corta mulungú;

Praieiro que tem vergonha

Não fala com guabirú.
}

Compreende-se perfeitamente o seu entusiasmo pela Revolta Praizira. Era uma rebelião de cunho caracteristicamente social. Movimento da plebe oprimida contra opressores mais bem aquinhoados. Luta de famintos contra nababos. $E$ os revolucionários pernambucanos de 1848 e 1849 mancharam de sangue e sol as ruas do Recife. Depois da propaganda abolicionista, nāo há em tôda á obra castroalvesca, atitude que mais formosamente marque o seu papel de poeta nāo dizemos apenas social, mas socialista, do que a sua adesāo, em entusiasmo e fé, à Revolta Praieira. Ficou sua lira ao lado dos cavalgados contra todos os Cavalcantis opressores; ao lado do nacional pauperizado em contraposiçāo ao "marinheiro" parasitário e enriquecido; ao lado dos pardos do Recife contra os brancos, às vêzes azulecidos de sangue holandês e encastelados nos engenhos.

A Revolução, pela profundidade do seu cunho hưmano, transcendia de muito aquêle movimento de liberais desempregados, co- 
mo Nabuco chega a insinuar ter sido a Revoluçāo Paulista de 1842. Esclarece Figueira de Melo, chefe de polícia do tempo: "Os jornais da oposiçāo nascida em 1842, por motivos de simpatia nascida com a Rebeliāo de Sāo Paulo e Minas, limitaram-se a princípio à censura dos atos do Govêrno provincial, bem depressa, sob pretexto de derrocar a suposta exclusiva influência de uma família, passaram a guerrear os cidadāos mais respeitáveis pelas suas relações, riqueza, cargos, saber e probidade... a açular o ódio dos nacionais contra os estrangeiros, principalmente os portuguêses... a inocular, nas classes baixas da sociedade, nāo o nobre sentimento de igualdade perante a lei, mas o sentimento do orgulho, pelo qual se julgavam ter direitos que sòmente dão a ilustração, os serviços e as virtudes, a proclamar enfim que o povo estava oprimido na realidade por déspotas furiosos..." (1).

A Rebeliāo Praieira tinha um sentido inquestionàvelmente social e seu espírito era o mesmo que justificava a apariçāo de duas autênticas figuras de socialista, coincidentes com aquêle periodo da vida nacional: Abreu e Lima e Antônio Pedro Figueiredo, êste provàvelmente a maior figura do socialismo brasileiro no século passado. Caracteriza-o Alfredo de Carvalho: "Abraçou com entusiasmo as doutrinas de Theodoro Jouffroy, às quais soube dar um cunho individual, modificando-as em parte ao influxo das teorias econômicas de Saint Simon, Owen e Fourier" (2). Redigiu um jornal "O Prógresso", de importância fundamental à história das idéias no Brasil. Seus escritos revelam uma personalidade forte, originalíssima para o meio, genial, imunisada da verborragia imperante, sabendo olhar concretamente para o cerne das cousas, sem turbar a visāo com a muralha das palavras de que o Romantismo coevo as revestia. Tinha - como aliás Abreu e Lima, a quem superava, como se diria hoje, por sua melhor politizaçāo conceito claro do problema da luta de classes: "O sofrimento social, proveniente da incoerência das relações que ora existem entre os homens, como produtores, distribuidores e consumidores, continua a manifestar-se claramente nas partes mais ricas e civilizadas da Europa, por uma divisāo cada vez mais profunda entre as classes que gozam ociosas e as que trabalham quebrantadas pela miséria" (3). E estruge o seu clarim revolucionário, desta vez não tuba da Revolução Francesa, mas sonoro prenúncio da Terceira Internacional: "Que nos resta fazer? Esperar melhores tempos. Quais sāo êsses tempos? Aquêles em que as rosas florescem Que rosas, brancas? Nāo, vermelhas" (4).

(1). - MELO (Figueira de), Crônica da Rebelião Praieira. Tipografia do Brasil. J. I. La Roche. Rio, 1s5̃o, Pág. 3.

(2) . - CARvaliro (Alfredo de), Estudos Pernambucanos. A Cultura Acadêmica. Recife, 1907. Pág. 72.

(3). - In QUINTAS (Amaro), o sentido Social da Revolugão Praieira. Imprensa. Oficial. Recife, 1945. Pág. 14

(4). - Ibidem. 
Possuia a crença de que a sorte do povo nāo melhoraria sem que se efetuassem modificações substanciais na infra-estrutura econômica: "Que sāo as reformas politicas sem as reformas sociais? Uma máscara e nada mais" (5).

Nāo é homem apenas para inócuas utopias, sabe apontar de naneira concreta o caminho da soluçăo e prega em meio àquela atmosfera violentamente liberalizada, santificadora da livre iniciativa, a teoria do intervencionismo estatal pleno, com o fito de regular o mecanismo das relações entre os homens. "Nós também pretendemos, é que o Govêrno, como representante da sociedade inteira, intervenha nos fenômenos da produçāo, distribuiçāo e consumo para regulá-los..." (6).

E descria corajosamente dos mitos mais caros do tempo: "De feito, que papel podem representar a Igualdade, a Fraternidade e a Liberdade nas nossas sociedades modernas? Que é a igualdade onde pequeno número de privilegiados gasta na ociosidade o produto do trabalho de milhares de seus irmāos? Que é Fraternidade num grêmio social que deificou o egoismo sob tôdas as formas.... Que é que pode significar o vocábulo Liberdade numa sociedade em que as massas dependem de um pequeno número de homens que de fato exercem sôbre elas um direito de vida e de morte, por mercê do capital?" (7).

E sabe que a raiz dos males está no latifúndio: "Êste regime arbitrário provém da organizaçāo atual da propriedade no irterior" (8).

Não resta dúvida de que estamos diante de uma formidável figura de precursor.

O mentor ideologico da Revolta Praieira foi o tribuno Borges da Fonseca, de significaçāo na vida de Castro Alves não tão bem. esclarecida como se devera.

Por sua influência, é que os revolucionários acabam lançando manifesto ao mundo em que preconisam: 1.o) voto livre e universal do povo brasileiro; 2.o) plena liberdade de comunicar os pensamentos por meio da imprensa; 3.o) trabalho como garantia de vida para o cidadāo brasileiro; 4.o) comércio a retalho para os cidadãos brasileiros; 5.o) inteira e efetiva independência dos poderes constituidos; 6.o) extinçāo do poder moderador e do direito de agraciar; 7.o) elemento federal na nova organização; 8.o) completa reforma do poder judicial em ordem a assegurar as garantias

\footnotetext{
(5). - Ibidem.

(6). - Ibidem.

(7). - Ibidem.

(8). - Ibidem.
} 
dos direitos individuais dos cidadāos; 9.o) extinçāo do juro convencional; 10.o) extinçāo do atual sistema de recrutamento (9).

Deixaremos para outra oportunidade as reivindicações pròpriamente econômicas. No seu conjunto, vê-se que a grande aspiraçāo que transluz dêste Decálogo é a da organizaçāo da Liberdade. Outro nāo é o sentido do século. Os vários itens da Táboa da Lei Praieira harmonizam-se num feixe homogêneo de liberalismo $\mathrm{e}$ as suas reivindicaçóes continuam sob outra roupagem ou com a mesma, repercutindo pelo século a dentro e avançando mesmo pela nossa centúria.

Direito basilar é o do voto, e, nesse particular, o debate do século oscila com variações de nuances entre as antimonias: eleiçāo indireta - eleiçāo direta, sufrágio restrito ou sufrágio universal. Em 1860, o pleito já podia realizar-se sob o império da chamada lei dos círculos, que desloca de certo modo o eixo de gravitaçāo do poder eleitoral do Govêrno central em direçāo dos régulos regionais. A melhoria foi ilusória. De qualquer maneira, tornava possivel a vitória nas urnas de Otaviano, Ottoni e Saldanha Marinho, marcando o que alguns considerariam um renascimento do principio democrático. O problema continua a agitar-se e em 1869 , num programa famoso, o Partido Liberal inclui a necessidade da reforma eleitoral. sempre com o objetivo do aniquilamento do decantado Absolutismo do Imperador. Em 1871 Castro Alves intervem no debate: "A terra que realizou a emancipaçāo dos homens, há de realizar a emancipaçāo das mulheres. A terra que fêz o sufrágio universal näo tem o direito de recusar o voto da metade da América".

$\mathrm{Na}$ Exortaçāo acima transcrita, a terra que já havia realizado o sufrágio universal era os Estados Unidos. O exemplo norte-americano, agora como em outros momentos, passava a exercer a sua seduçāo sôbre o espírito do poeta. Com muita probabilidade, teria êle compulsado os trabalhos de ilustre contemporâneo seu, Tavares Bastos, emérito pregador das instituições do Norte pelas terras do Sul. Poderia ter lido os comentários do pensador alagoano, aparecidos em "A Frovincia", editada em 70 ...". . e os consequientes com a politica abolicionista triunfante, fizeram estender ao país inteiro o sufrágio universal e a igualdade de raças ou côr" (10). Castro Alves avança o sinal, mesmo tendo-se em vista a legislaçāo norte-americana: queria chegar ao voto feminino. O sufrágio teria que ser direito de homem, de mulher, de branco, de pardo, de preto, de amarelo, e necessàriamente extinta a populaçāo de barões, de duques, de marqueses, de viscondes, de adornados com a Ordem da Rosa, uma vez que, tal o preconício do Decálogo libertador, estaria extinto o direito de agraciar, medida que só álcançaria a sançāo com a carta de 1891 .

(9). - MELO REGO, Rebelião Prabira. Imprensa Nacional. Rio de Janeiro, (10). - TAVARes BAstos, A Província. 2a. Edição. Companhia Editora Nacional. São Paulo. Págs. 49-50. 
O problema da liberdade sempre trouxe implicito o da livre expressāo do pensamento. O seu veículo natural é principalmente á lmprensa. E Castro Alves é jornalista. Redige "O Futuro" em Recife, onde também faz a-introduçāo do jornal "A Luz", em que e polemista e vasa as suas idiosincrasias para com Tobias Barreto. Colabora no periódico de Borges da Fonseca. Para êle, a Imprensa encontrou o país adotivo na América ("O Livro e a América") e concebe-a apenas como um instrumento de luta contra opressāo ("Deusa Incruenta") :

Rugiram de terror ao ver-lhe o rir sublime...

O sátrapa, o chacal, a tirania, o crime...

$\mathrm{O}$ abutre, o antro, o mocho, o êrro. a escravidão...

É porisso que ela teve de seguir as vicissitudes da própria $\mathrm{Li}$ berdade, no verbo romano de Cícero, na queda da Bastilha, nas peregrinações de Lord Byron, na tragédia polonesa com Mickiewickz e Kociusko.

O quinto e o sexto item se entrosam. A dependência de poderes se dava mercê de uma hipertrofia do Trono, que avassalava tôdas as Fotestades, marcando de seu dedo a Justiça e a Lei, atra. vés do Poder Moderador. Institui-o o primeiro Pedro, na Constituiçāo outorgada e logo aparecem recriminações como as de Frei Caneca, para quem êsse quarto poder "era a chave mestra da opressāo brasileira e o garrote mais forte da liberdade dos povos" (11). Depois do $7 \mathrm{~d} z$ Abril, apareceria a censura tonitroante de Teófilo Otoni: "Somos de opiniāo que se deve lentamente republicanizar a constituição do Brasil, cerceando as fatais atribuições do Poder Moderador....". Nāo tardaria a Câmara a aprovar uma reforma constitucional em que, ao lado da federaçāo, preconisasse a morte do Poder malquisto, assim como abolindo o carátér vitaíicio do Senado. O Senado foi contra... O combate continuaria pelo Império a dentro. $O$ robustecimento da autoridade monárquica tinha inclusive a designaçāo depreciativa de imperialismo, tāo verberado por Tito Franco de Almeida (12). Grande parte da história política de todo um longo período do Império bresileiro revela-nos a crença vigente em quase todos os espíritos, da periculosidade do Govêrno com o conseqüente empenho de, tanto quanto possivel, aparar os cabelos do Sansão todo podercso.

Borges da Fonseca participara do movimento de 7 d? Abril e, por seu intermédio, as convulsões nativistas e libertárias daquela fase de nossa história vem encontrar naturalmente a poesia de Castro Alves. Fonseca é o traço de uniāo entre os exaltados daquela

\footnotetext{
(11). - In VAIADÄO (Alfredo), Da Aclamacão a Maioridade. Companhia Editora Nacional. São Paulo, 1939. Pág. 106.

(12). - ALMEIDA (Tito Franco de), o Conselheiro Francisco José Furtado. Companhia Editora Nacional. São Paulo, 1944.
} 
hora de civismo e caos e a retórica fulgurante do Condor. O Decálogo do turbulento jornalista praieiro já se apresenta limítrofe da República sonhada pelo Poeta. Faltou-lhe a aboliçāo, é claro. Mas o seu sétimo mandamento já sonha com o "elemento federal na nova organizaçāo." Elemento federal que acabaria sendo o penúltimo passo em direção da República e que foi acentuadamente um dos temás prediletos da geraçāo de Castro: Joaquim Nabuco, Ruy Barbosa, Tavares Bastos que, no tempo, iam transformando em discurso parlamentar, em comício de rua, em artigo de jornal, em ensaio sócio-político, em projeto de lei, em programa de partido, e o segundo dêles em açāo revolucionária, em verbo apostolar psla República a dentro, a ideologia vestida de metáforas do moço poéta.

O problema da soberania liga-se umbelicalmente ao da organizaçāo judiciária (item oitavo). Por aí, as experiências se multiplicaram, atingindo o extremo do liberalismo no Código de Processo de 1832, que sagrava o princípio da eleiçāo para a justiça, a policia, a guarda nacional e parte do corpo de jurados. No caso da Guarda Nacional, os cabos e demais inferiores eram eleitos pelos guardas. O tenente coronel comandante, o major, o ajudante, o alferes porta bandeira, eleitos pelos furriéis e sargentos... Compreendem-se os frutos dêste regime; a criaçāo de uma justiça partidária e de uma polícia igualmente partidária. Conta Joāo Brígido. que, no Ceará, em poucos meses de sua vigência levantaram-se forcas por tôda a parte, para castigo dos elementos do partido conirário (13). "Quando a justiça ao revés, passava para um regime de centralização, as queixas continuavam do mesmo modo..." A lei de 3 de dezembro centralizou o Império nas mãos do ministro da Justiça, generalíssimo da polícia, dando-lhe, por agentes, um exército de funcionários hierárquicos, desde o presidente de província e chefe de polícia até o inspetor de quarteiräo (14):

Neste ponto como em outros, a Revolta Praieira agita uma aspiração geral do século. Como ambição geral do século é a relativa à extinçāo do recrutamento e da Guarda Nacional. Di-lo Tavares Bastos: "Abolir o recrutamento, preenchendo-se o exército e a armada por engajamentos voluntários; abolir a guarda nacional, criando-se nas paróquias a guarda cívica policial formáda pelas câmaras municipais, tais sč̀o as idéias de eminentes liberais sôbre a nossa organizaçāo militar" (15). Isto, em "A Província", editada em 70. Em 1873, em seu esbôço de reforma eleitoral e parlamentar acusa o recrutamento como sendo utilizado para fins de perseguiçāo política: "Se o próprio votante nāo é o padecente, sofra na pessoa de outrém; recrutam o filho e o desterram, por exem-

(13). - In VIANA (Oliveira), Problemas de Polítiea Objetiva. Companhia Edi(14). - BASTos (Tavares), Olora citada. Pág. 159.

(15). - Ibidem. Pág. 175. 
plo. Quantas vítimas políticas devorou o Paraguai! Quantas se imolam diàriamente!" (16).

O povo queixava-se tanto quanto Tavares Bastos:

\author{
Deixo espôsa que me ama, \\ Deixo filhinhos menores, \\ Mil amigos e parentes \\ Deixo por teus arredores. \\ Livre nasci, livre sou, \\ Militei com Pedro Ivo, \\ Porém p'ra ser recrutado \\ Não julgo isto motivo (17).
}

Já na Bahia do poeta, o recrutamento assumia feições bárbaras. Entāo "os homens válidos foram procurados como feras... varejavam-se as cásas, arrancavam-se rapazes ocultos nos armários..." (18).

Com todos os aspectos que pudesse revestir esta condenaçāó do sistema de engajamento entāo utilizado, temos que ela, na verdade, refletia as aspirações de um povo nascido para a indolência e paz, insuscetível de entusiasmos belicosos. $O$ batalhāo de Trigo de Loureiro que se formou às vistas do poeta no Recife, para ir ao Paraguai inspirou discurso e poemas, desfilou garboso pelas

(16). - BASTOS (Tavares) Os Males do Presente e as Esperangas do futuro. Companhia IEditora Nacional. São Panio, 1939. I’ág. 200.

(17). - PERIEIRA DA COSTA, Folclore Pernambucano. Imprensa Nacional. Rio, 1908. Pág. 429.

(18). - QUERINO (Manuel), A Bahia de Outrora. Liviaria Progresso Editora. Salvador, 1946. Pág. 182.

Koster tambem se refere às agruras do recrutamento: "Nesse tempo foram dadas ordens de recrutamento para os Regimentos de Linha pelo Governador. Os homens exigidos são obrigados a esse serviço E' nessa ocasião que a tirania tem o seu esplendor, que o capricho e o arbítrio se aliam e que a mais injusta parcialidade prevalece, e se executa a mais intolerável opressão. O fato é que todo o país se arma, uns contra os outros, $€$ todos os meios de surpreender cada um são usados pelo vizinho." (Viagens ao Nordeste do Mrasil - Truducāo de Luiz da Câmara Cascudo. Companhia Editora Nacional. São Paulo, 1942, pág. 389). Agassiz não tivera melhor impressão: "Tivemos esta manhā uma triste prova da brutalidade com que se procede ao recrutamento... Três fndios... foram trazidos para bordo de nosso navio, fsses infelizes tinham as pernas presas num grosso barrote de madeira, contendo orifícios que mal davam para deixar passar os tornozelos. Só se mexiam por necessidade e com grande dificuldade. Vieram meio empurrados, e meio icados para bordo, e um dêles, prêsa de febres, tinha tais calafrios... (Viagem ao Jrasil. Traducão de Edgard Sussekind de Mendonça. Companhia Editora Nacional. São Paulo, 1938. Págs. 412-413).

Essi aversão ao recrutamento é outro aspecto que assume em nossa terra o conflito entre o poder público e a ordem privada. Há nesse episódio não só a antipatia ao servico militar, como ainda a oposição à lei em si, como forca coercitiva apenas, e para um povo de tendências anárquicas, rebelde a qualquer especie de coerção. Daí o caráter repulsivo que sempre assumiu entre as camadas de nosso povo a palavra "obrigatório". O vovo reagia contra o recrutamento obrigatório como iria criar embaraços as próprias tentativas esporádicas que se iam fazendo de instalaģāo do ensino obrigatório, como posteriormente chegaria a fazer uma revolução por causa da vacina obrigatória... E nos nossos dias assistimos à impossibilidade do voto obrigatório. 
ruas da cidade e nāo partiu. A parte da poesia de Castro Alves inspirada na guerra contra Lopes é minima, sobretudo se sa tiver em conta que jamais houve em tôda a nossa evoluçāo histórica assunto que de tal modo houvesse fascinado os poetas contemporâneos. Todos êles, nesta emergência, se sentiam no dever de colaborar com a sua ode exaltadora dos feitos dos heróis de Riachuelo ou Avai. Castro Alves portou-se com relativa discreçāo. Poucos os poemas seus consagrados ao conflito. E à margem de um dêles, chegou a escrever: "Nāo se publica". Analisando-o, ver-se-á que é tão bom ou tão mau como grande parte da obra do vate. De modo que a condenaçāo em absoluto nāo deve ter sido formulada por considerações estéticas. O Index a que relegara o poema pode significar aversāo pelo tema guerreiro ou especificamente por uma luta sem glória em que o maior Império da América do Sul aparentava fraquejar ao poderio da minúscula república paraguaia. Sintomático dêste ponto de vista o seu "Deusa Incruenta". Diz o poeta que é antítese à "Terribilis Dea" de Pedro Luiz. O poema dêste é uma exaltaçāo da guerra, em geral. A antítese castroalvesca por aí é oposta à guerra. O poema do fluminense é ainda inspirado na Batalha do Riachuelo e uma antitese a um poema feito para exaltar, indiretamente embora, a façanha dos capitaneados do Almirante Barroso, mostra sintomas que nāo podem ser considerados de aprovação para com o vencedor da celebrada batalha naval.

Cestro Alves, na terra bahiana, nasceu entre céu e arvoredo e em atmosfera assim bucólica desenvolve-se-lhe a infância. Ortega y Gasset, quando contrapõe Castela à Andaluzia, afirma que a primeira é belica, o que vale dizer contra o campo, por sla considerado apenas um campo de batalha, enquanto a segunda, é agrária, cu seja pacifica (19). Donde: o amor à terra enquanto campo, enquanto verdura, enquanto pássaro, árvore e peixe, ao mesmo iempo que nutre a transbordante poesia da natureza em Castro Alves, pode lastrar-lhe o pendor pacifista.

Imagem de um Brasil que acabaria incluindo em sua Carta Constitucional e interdiçāo da guerra de conquista, Castro Alves por ai é muito mais simbolo da pátria brasileira que Tobias Barreto, estrugindo "em tuba canora e belicosa" no seu "Os Voluntários. Pernambucanos" ou entāo a inspiraçāo acendida de Vitoriano Palhares, o esquecido poeta por excelência da Guerra do Paraguai. A "Deusa Incruenta" é muito mais Brasil que os quadros de batalha ie Pedro Américo ou Vitor Meireles.

(19): - ORTEGA Y GASSIET, Teoria de Andalucin, Revista do Occidente. Madrid, 1944, Págg. 20 e 21. 
A Revoluçāo Praieirà deu à História e à poesia nossa a figura de Pedro Ivo. Dêste, uma opiniāo contemporânea, a do Ministro dia Justiça, pelos idos de 1850, informava: "Pedro Ivo, um dos chefes da Revolta, espírito refratário, receioso sem dúvida do rigor ùas leis, porque năo é sòmente réu de crimes politicos, mas também de outros e desertor do exército, ligou-se ao bando de Caetano Alves que há tempo infesta as matas de Água Preta, ali se conserva errante a saindo sòmente às ocultas, para assolar e devas:ar os povos vizinhos que pode surpreender" (20).

A condição de "espirito refratário" nunca impediu a criação dio mito do herói. O ciclo do cangaço, no Nordeste Brasileiro, pode atestá-lo. Admira-se Fedro Ivo, por todos os motivos que lastreiam o impulso da Revolta Praieira, mas admira-se-o pelas mesmas razões porque se admira e se louva Antônio Jesuino ou Lampečo. O sertanejo cultua a valentia e o brio e procura sempre ver na gênese do fênomeno social do bandoleirismo um sentimento generoso. O desértico isolamento do sertāo, distancia-o do poder público e o crime aparece como sendo a forma primitiva e autóctone de justiça (21). Fercebe-se o nexo inefável que existe entre o tema de Pórcia - tia do poeta com uma aventura de amor terminando em sangue - e o de Pedro Ivo, a primeira procurando entremostrar-se bruxoleante pelos desvāos das estrofes equivocas, o segundo, pleno e clamoroso nas radiaçóes dos versos do poeta.

A legenda de Pedro Ivo emerge da voz do povo, vai aos jornais da oposiçāo e é posteriormente nutrida pelos poetas. No caso, temos em Álvares de Azevedo, um precursor de Castro Alves, nāo cabendo aqui a diferenciaçāo que entre a produçāo de ambos fêz Edison Carneiro (22), a de que o poema de Azevedo seria monarquista enquanto o de Castro Alves estremecia de pensamento republicano. Nāo é monarquista um poema em que o herói é exaltado como "filho do povo" e de que se poderia ter dito:

(20). - Melo Rego, Obra citada. Pág. 122.

(21). - Cfr. BARRoso (Gustavo) Ao Som da Viola - sem ref. ed. Rio de Janeiro, 1949. Pág. 283 e CASCUDO (Luiz Camara), vaqueiros e Cantadores. Livraria do Globo. Pôrto Alegre, 1939. F’ág. 116 - Schlichthorst, que esteve no Brasil por 1825-1826 encarece a necessidade desta justiça feita pelas próprias mãos: "Duelos e facadas... têm sua utilidade social. Evitam grosserias e chalaças ofensivas em todas as rodas, tornam os homens discretos e respeitosos para com o belo sexo..." (O Rio de Janeiro como c. Traducão de Emy Dodt e Gustavo Barroso. Lditora Getulio Costa. Rio, s. d. Pág. 31).

(22). - CARnerro (Edison), Trajetórla de Custro Alves. Iśdotorial Vitória. Rio de Janeiro, s. d. Pág. 41. 
Alma cheia de fogo e mocidade,

Que ante a fúria dos reis não se acobarda,

Sonhava nesta geração bastarda,

Glória... e LIBERDADE! (23)

Nāo pode em absoluto ser monarquista uma ode em que reponta uma estrofe desta natureza:

Nem sangue de Ratcliffe o fogo apaga

Que as FRONTES POPULARES embriaga,

Nem do herói a cabeça decepada,

Imunda, envolta em pó, ensanguentada,

Assusta a multidão que ardente brada

E TRONOS DEPEDAÇA! (24)

E Castro Alves coroa o seu herói de halo da mais pura legenda:

Indà me lembro... Era, há pouco,

A luta!... Horror!... Confusão!...

A morte voa rugindo

Da garganta do canhão!

O bravo a fileira cerra!

Em sangue ensopa-se a terra!

E o fumo - o corvo da guerra -

Com as asas cobre a amplidão.

Cheguei!... Como nuvens tontas,

A bater no monte - além,

Topam, rasgam-se, recuam...

Tais a meus pés vi também

Hostes mil na luta inglória...

Da pirâmide da glória

São degraus... Marcha a vitória

Porque êste braço a sustem.

Opina Joaquim Nabuco que, na história da pregação republicana, é Borges da Fonseca-o maior de todos. Era o tribuno, como ainda o pasquineiro atrevido e a história dos seus jornalecos é contribuiçāo de relêvo à própria história das idéias em nosso país. Hélio Viana dá um excelente relato em tôrno de sua vida. Foi o maior dos panfletários do Império. Volta e meia, era vitima de processo (25) "pelo abuso de liberdade de comunicar os pensamentos pela Imprensa". Por 1830, autobiografando-se, diz estar "à frente da direçāo suprema do Partido Liberal Revolucionário, partido republicano" (26). Fublica no Rio "O Repúblico" cujo nome, nāo obstante as declarações em contrário do jornalista, sugere-lhe as tendências. No "Tribuno", jornal de Borges, é que foi

(23). - AZEVEDo (Álvares de), obras Completas. Companhia Editora Nacional. Sa. Jdição. 1942, Pág:s. 309-310).

(24). - AZZVEDO (Alvares de), Obra citada, volume I, página 165.

(25): - VIANA (Helio), Contribuigão a História da Imprensa Brasileira. Im-

(96) prensa Nacional. Rio, 1945. Págs. 538-539.

VIANA (Hếlio), Obra Citada. Pág. 540 
publicado o poema de Castro Alves "O Povo ao Poder". Esta poesia aparece na ediçāo de Afrânio Peixoto, recolhida de tradiçāo oral, com uma estrofe completamente omitida, além dos inevitáveis equívocos, dada a origem da versāo. Êsse poema é dos mais importantes à caracterizaçāo de um pensamento político. E' uma clara profissēo de fé republicana e democrática.

Aparece o poema sem indicaçāo de autoria. E para todos aquêles que sabem o Narciso que é o nosso poeta, ocorre que só mesmo razões muito ponderáveis é que teriam sido capazes de impedir a aposição da assinatura à ode libertária. $\mathrm{O}$ anonimato serve apenas para atestar o caráter revolucionário do poema, publicado * num jornal que havia sentido na carne vários processos por abuso de expressāo...

O título diz "O Povo ao Poder". Democracia. Democracia. Democracia. Faz a apologia da liberdade de reuniāo, espesinhada naquele momento pelas patas de cavalo dos energúmenos da policia. Esta havia proibido os comícios republicanos e Castro Alves entoava o canto para protestar contra a arbitrariedade insólita. E o poeta reivindicava para o povo, o direito à praça, o que vale dizer o direito ao protesto, o direito ao grito, o direito à Revoluçāo. 